\title{
$\mathrm{BIM}$ 기반 초기 설계 단계 철근 물량 산출 프로세스 구축
}

\author{
송 치 호$^{1} \cdot$ 김 치 경 ${ }^{1} \cdot$ 이 시 은 $^{2} \cdot$ 최 현 철 ${ }^{3+}$ \\ ${ }^{1}$ 단국대학교 건축공학과, ${ }^{2}$ 백석대학교 정보통신학부, ${ }^{3}$ 창소프트아이앤아이 기술연구소
}

\section{Establishment of Rebar Quantity Estimation in BIM-based Initial Design Phase}

\author{
Chi-Ho Song, Chee-Kyeong Kim, Si Eun Lee and Hyunchul $\mathrm{Choi}^{{ }^{+}}$ \\ ${ }^{1}$ Department of Architectural Engineering, DanKook Univ., Yongin, 16890, Korea \\ ${ }^{2}$ Department of Information \& Communication System, Baekseok Univ., Cheonan, 31065, Korea \\ ${ }^{3}$ ChangSoft I\&I Research Center, Seoul, 06173, Korea
}

\begin{abstract}
In the meantime, looking at the present status of how to estimationte the quantity of rebar based on 3D BIM getting the limelight in these days, commercial BIM tools provide rebar modeling functions however it takes a vast amount of modeling time for modeling of rebar in use of that function hence there is no BIM software at present for practical use. Therefore, in this study, we organized and presented a practical rebar quantity estimationtion process in BIM-based design work-site and intended to develop a program named Rebar Automatic Arrangement Program - hereinafter called RAAP - which enables automatic rebar arrangement based on much more precise cross-sectional information of bars in column, beam, slab and wall than the one from existing 2D method under the conditions without any cross $^{-}$sectional information in the initial design phase. In addition, we intended to establish rebar quantity estimationtion process in the initial design phase through interworking of modeling \& quantity estimationtion functions in consideration of joint, anchoring length of BuilderHUB as a BIM software with RAAP. The results from this study are practical in developing a technology that is able to estimationte quantity with more improved reliability than the one from existing 2D-based methods with less effort when the quantity of framework is estimationted in the uncompleted state of cross-sectional design for structural members in the initial design phase of a construction project. And it is expected that it could be utilized as a basic study from which a reasonable quantity estimationtion program can be established in the initial design phase.
\end{abstract}

Keywords : the initial design stage, BuilderHUB, BIM, reinforcement algorithms, quantity take-off

\section{1. 서 론}

전통적인 견적프로세스에 의한 철근 물량 산출은 견적 엔지 니어에 의한 골조, 설비, 마감 물량을 산출한다. 콘크리트, 거푸집, 설비, 마감 물량은 $3 \%$ 이내 오차로 견적이 이루어 지지만 철근의 경우 이음, 정착, 개구부의 보강근, 단차 상세, 시공 보조근, 자투리 철근 등 실제 배근 상세 반영의 어려움과 예측이 어렵기 때문에 많게는 $10 \%$ 까지의 오차가 발생하여 전문건설회사, 발주자 등 사이에 많은 갈등을 야기하고 있다.

최근 각광받고 있는 $3 \mathrm{D} \mathrm{BIM}$ (building information

\footnotetext{
${ }^{\dagger}$ Corresponding author:
}

Tel: +82-10-6395-1321; E-mail: jissi@snu.ac.kr Received August 5 2016; Revised August 31 2016; Accepted September 12016

(C) 2016 by Computational Structural Engineering Institute of Korea modeling 이하 BIM)기반 철근 물량 산출 현황을 살펴보면 상용 BIM 도구들이 철근 모델링 기능을 제공하지만 그 기능을 이용해서 철근을 모델링하려고 하면 방대한 양의 모델링 시간이 소요가 되어 현재 실용적으로 사용할 수 있는 BIM 소프트 웨어는 없다. 그래서 많은 기술자들이 상용 BIM 소프트웨어에 Application Programming Interface(이하 API)를 이용 하여 철근 모델링 생산성을 향상시켜서 실용화시키고자 하였 지만, 실용화된 기술은 아직 전무한 상황이며, 결과적으로 BIM 기반 철근 물량 산출 프로세스는 $\mathrm{BIM}$ 기술의 확산에도 불구 하고 철근 물량 산출 프로세스는 부재한 상황이다.

This is an Open-Access article distributed under the terms of the Creative Commons Attribution Non-Commercial License(http://creativecommons. org/licenses/by-nc/3.0) which permits unrestricted non-commercial use, distribution, and reproduction in any medium, provided the original work is properly cited. 
이에 본 연구에서는 $\mathrm{BIM}$ 기반 설계 현업에서 실용적인 철근 물량 산출 프로세스를 정리 및 제시하고, 초기 설계 단계의 단면 정보가 없는 상태에서 기존의 $2 \mathrm{D}$ 방식에 비하여 보다 정확하게 기동, 보, 슬래브, 벽체의 철근 단면 정보를 자동으로 배근해 주는 프로그램인 Rebar Automatic Arrangement Program(이하 RAAP)을 개발하고자 한다. 또한 BIM 소프트웨어인 BuilderHUB(이하 $\mathrm{B} / \mathrm{H}$ )의 이음.정착 길이를 고려한 모델링 및 물량 산출 기능과 $\mathrm{RAAP}$ 를 연동하여 초기 설계 단계의 철근 물량 산출 프로세스를 구축하고자 한다.

\section{2. 예비적 고찰}

\section{$2.1 \mathrm{BIM}$ 소프트웨어 주요 기능 및 한계점 분석}

현재 국내에서 활용되고 있는 BIM 도구는 크게 Revit, ArchiCAD, Tekla, Allplan 등 사용되고 있다. 하지만 현재 골조공사에서 있어 이러한 BIM 도구의 활용성은 초기 단계에 머물러 있으며, 이 도구들이 실제 골조공사의 생애주기에 걸친 활용성은 설계 단계에서 높지만, 실제 시공 단계에서는 그 활용도가 매우 낮아진다.

본 연구에서는 골조공사 비용의 많은 부분을 차지하며, $\mathrm{BIM}$ 기술의 기술적 한계로 지적되고 있는 철근공사에 적용되고 있는 상용 BIM도구의 활용도를 분석하였다.

Table 1은 현 구조설계 업무에서 $\mathrm{RC}$ 구조물을 대상으로 사용되는 BIM S/W의 특장점 및 주 기능에 따라 Modeling (M), Shop Drawing(D), Quantity take-off(Q)의 각 단계별 적용성을 정리·분석한 것이다.
Table 1에 나타난 BIM S/W들은 구조설계의 전 단계를 다룰 수 있는 통합설계 $\mathrm{S} / \mathrm{W}$ 가 없다는 것을 알 수 있다. 이러한 이유로 구조설계 업무는 분리되어 수행될 수밖에 없는 현실이다. 각 업무주체별로 다른 $\mathrm{S} / \mathrm{W}$ 를 사용하게 되므로 $\mathrm{S} / \mathrm{W}$ 간의 호환 문제가 발생하여 구조설계로부터 받은 기본 도면을 통해 구조해석 모델과 같은 속성 값을 갖는 모델을 재 모델링해야 하는 번거로움이 있다. 설계 정보의 재사용율의 부재로 인하여 철근 배근이 구조적으로 매우 중요한 요소임 에도 불구하고, 대부분의 업무가 반복적인 수작업으로 이루어 지기 때문에 전 구조설계 업무가 노동집약적인 산업으로 인식 되어 왔다.

이에 Tekla Structures, All Plan 등의 실시설계 전문 $\mathrm{BIM} \mathrm{S} / \mathrm{W}$ 를 통해 이러한 문제를 해결하고자 하였으나, 디테일 모델을 생성하기 위해 사용되는 파라메트릭 컴포넌트의 경우 국내 실정에 맞지 않는 경우가 대부분이며, 때로는 컴포넌트의 파라미터 즉, 속성 값을 입력하는 과정이 $2 \mathrm{D}$ 기반으로 작업 하는 것 이상의 노력을 요구하는 경우가 발생하기도 한다. 또한 파라메트릭 컴포넌트는 단일 배근 개소에 대해서는 효율적일 수는 있으나, 건물의 규모와 형태에 비례하여 배근 개소가 증가 되는 경우 여전히 반복적인 과정을 거쳐야 하기 때문에 업무의 생산성은 매우 낮은 실정이다. 또한, Bentley Structures, All $\mathrm{Plan}$ 등의 경우 $\mathrm{API}$ 관련 기술 지원이 거의 전무한 상황이다.

이러한 $\mathrm{BIM}$ 툴의 기술적 한계(각 툴 간의 상호운용성, 지원 가능한 기능의 한계) 및 BIM data 활용의 한계로 각 단계별로 단순 반복적이고 비효율적인 정보의 재입력 혹은 중복되는 재 모델링 작업을 필요로 한다. 또한 이러한 과정의 순환은 설계변경 시 이와 같은 일련의 과정을 다시 거쳐야

Table 1 Main functions and features of each BIM S/W in RC structure design

\begin{tabular}{|c|c|c|c|c|c|}
\hline S/W(Vendor) & M & $\mathrm{D}$ & Q & Main functions & Features \\
\hline $\begin{array}{c}\text { Revit } \\
\text { (autodesk) }\end{array}$ & 0 & $\triangle$ & $\Delta$ & $\begin{array}{c}\text { Modeling of structure details, } \\
\text { To make rebar arrangement } \\
\text { drawings }\end{array}$ & $\begin{array}{l}\text { Adjusts drawings \& documents and provides } \\
\text { bidirectional linkage with structure analysis S/W/ } \\
\text { Available to make up shop drawing and drawing } \\
\text { details of RC structure \& steel structure }\end{array}$ \\
\hline $\begin{array}{l}\text { All plan } \\
\text { engineering } \\
\text { (nemetschek) }\end{array}$ & O & $\triangle$ & $\triangle$ & $\begin{array}{c}\text { Modeling of structure details, } \\
\text { To make rebar arrangement } \\
\text { drawings }\end{array}$ & $\begin{array}{c}\text { Direct compatibility with structure analysis S/W } \\
\text { such as Scia, etc. / Automatic rebar arrangement } \\
\text { available through fleet in rebar modeling / } \\
\text { Available of drawing details, qty estimationtion for } \\
\text { this on real time basis }\end{array}$ \\
\hline $\begin{array}{c}\text { Tekla structures } \\
\text { (tekla) }\end{array}$ & 0 & $\triangle$ & $x$ & $\begin{array}{c}\text { Modeling of structure details, } \\
\text { To make rebar arrangement } \\
\text { drawings }\end{array}$ & $\begin{array}{l}\text { Provides various structure materials, Accurate 3D } \\
\text { generation \& management of complicated } \\
\text { structures/Available of whole building processes } \\
\text { from concept design to manufacturing \& } \\
\text { construction control/Provides Open API }\end{array}$ \\
\hline $\begin{array}{l}\text { Bentley } \\
\text { structural modeler } \\
\text { (bentley systems) }\end{array}$ & 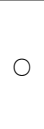 & $\times$ & $\triangle$ & Modeling of structure details & $\begin{array}{l}\text { Applicable to building, plant, concrete \& } \\
\text { lumber/Possible of drawings generation, quantity } \\
\text { estimationtion, performance analysis, etc. }\end{array}$ \\
\hline
\end{tabular}


하기 때문에 시공을 위한 결과물을 추출하기에 즉각적인 대응이 어려운 실정이다.

결과적으로 $\mathrm{BIM}$ 을 기반으로 한 $\mathrm{RC}$ 구조설계 업무의 효율 성과 생산성을 높이기 위해서는 작업들 사이에 요구되는 여러 절차의 효율적 통합 및 입출력에 요구되는 데이터들의 일괄 처리가 가능하도록 하는 $\mathrm{S} / \mathrm{W}$ 간의 상호운용성 개선 및 배근 상세모델링 자동화 시스템 개발이 요구되고 있는 실정이다.

\subsection{BuilderHUB}

본 연구에서 사용할 $\mathrm{B} / \mathrm{H}$ 는 건물골조의 상세설계와 정밀 견적에 특화된 3 차원 $\mathrm{BIM}$ 소프트웨어로, 다른 $\mathrm{BIM}$ 소프트
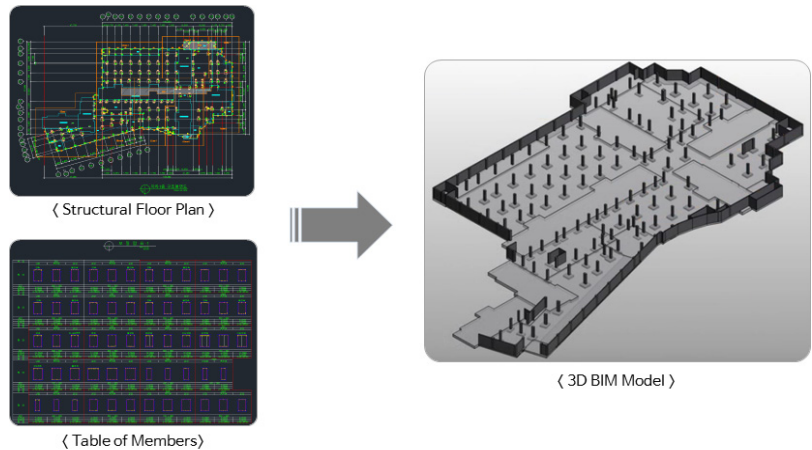

Fig. 1 Generation of 3D modeling through recognition of structural floor plan

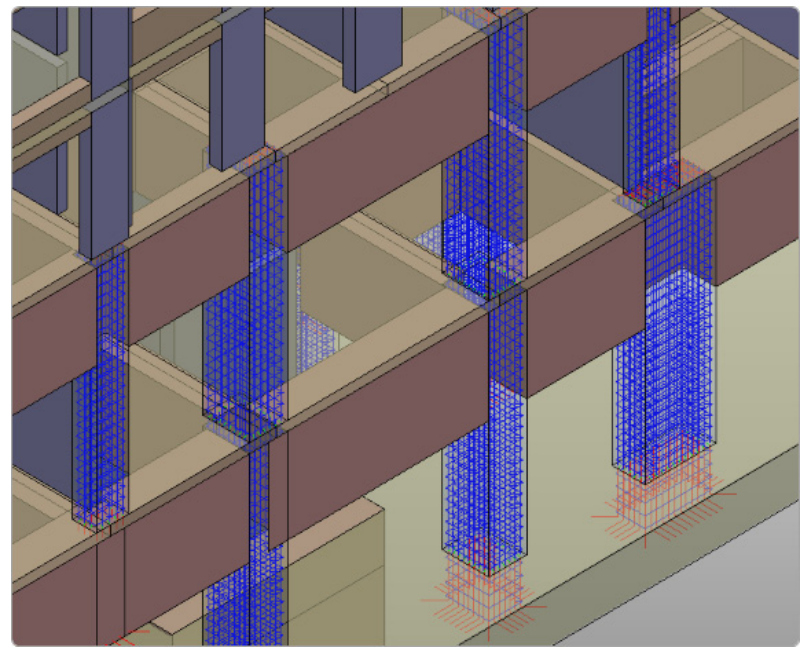

Fig. 2 Column arrangement Modeling

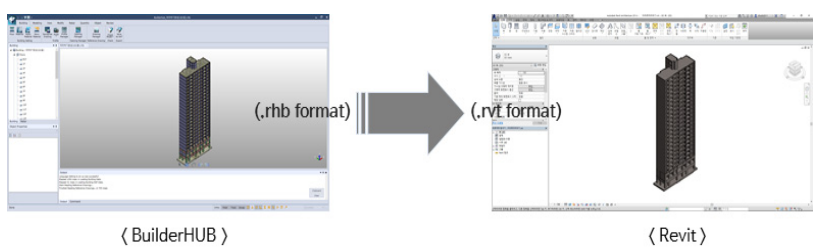

Fig. 3 Interworking with existing BIM S/W
웨어에 비하여 철근의 이음·정착 길이를 고려한 모델링 및 물량 산출이 쉽고 빠르고 가능하여 본 연구의 취지에 맞게 활용할 수 있어서 선정하였다. 또한, 국내·외 건설현장에 적용 되는 등 현장적용 효과가 입증된 바 있다.

Fig. 1은 B/H로 구조평면도 인식을 통한 3D BIM 모델을 생성한 그림이다. Fig. 2는 기둥의 철근 모델링이 완성된 화면이며, Fig. 3에서 볼 수 있듯이 상용 소프트웨어와 호환이 가능하다.

\section{BIM 소프트웨어 분석 및 개선 프로세스 제시}

앞서 수행한 각 $\mathrm{BIM}$ 소프트웨어 주요 기능 및 한계점 분석으로 현 소프트웨어 및 BIM 활용정도를 파악한 결과 철근 배근 모델링 등 소프트웨어의 부족한 기능을 보완하려는 연구가 많았다. 또한 철근 물량 산출에 있어 각 소프트웨어의 기능이 매우 미흡한 실정이며, 특히 초기 설계 단계의 철근 물량 산출은 거의 불가능한 지경이다.

따라서, 본 연구에서는 초기 설계 단계 철근 물량 산출에 있어서 $\mathrm{B} / \mathrm{H}$ 를 활용한 개선된 프로세스를 제시하고자 한다. 이에 대한 상세 내용은 다음과 같다.

첫째, $2 \mathrm{D}$ 기반의 도면출력을 위한 수작업에 의해 발생되는 피할 수 없는 오류와 다발적인 수정사항, 비효율적 노동 집약적인 업무 특성이 문제점이 된다. 철근콘크리트 구조 설계에 따른 배근 상세모델링 업무의 자동화 실현이 필요하다. 이를 위해 배근 설계 결과를 $3 \mathrm{D}$ 모델링의 현실적 활용이 가능하도록 $3 \mathrm{D}$ 상세모델링 단계에서 배근이 포함된 상세 모델을 자동 생성할 수 있는 자동 배근 시스템 개발이 필요하다.

둘째, 현재 BIM 소프트웨어의 철근 모델링 기능은 각 부재단위로 모델링을 해야하며, 많은 시간을 필요로 하고 이음·정착길이를 고려하지 않아 물량을 산출함에 있어 문제가 많다. 이에 대해 BIM 소프트웨어의 Open API를 이용하여 개선하고자 하는 연구가 많이 진행되었지만 아직 부족한 부분이 많이 있다. 이에 대해 $\mathrm{B} / \mathrm{H}$ 의 프로세스를 제시함으로 현 프로세스를 개선하고 한다.

셋째, 상용 $\mathrm{BIM} \mathrm{S} / \mathrm{W}$ 및 $\mathrm{B} / \mathrm{H}$ 의 초기 설계 단계의 단면 정보가 없을 경우 철근 물량 산출에 있어서 거의 불가능한 실정이다. 초기 설계 단계의 단면 정보를 생성해 주는 프로 그램의 개발이 필요하며, 이를 $\mathrm{BIM} \mathrm{S} / \mathrm{W}$ 와 연동하여 철근 물량 산출을 가능하게 하고자 한다.

이상의 제시한 해결방안에 따른 개선된 프로세스를 간략하게 그림으로 표현하면 Fig. 4와 같다. 


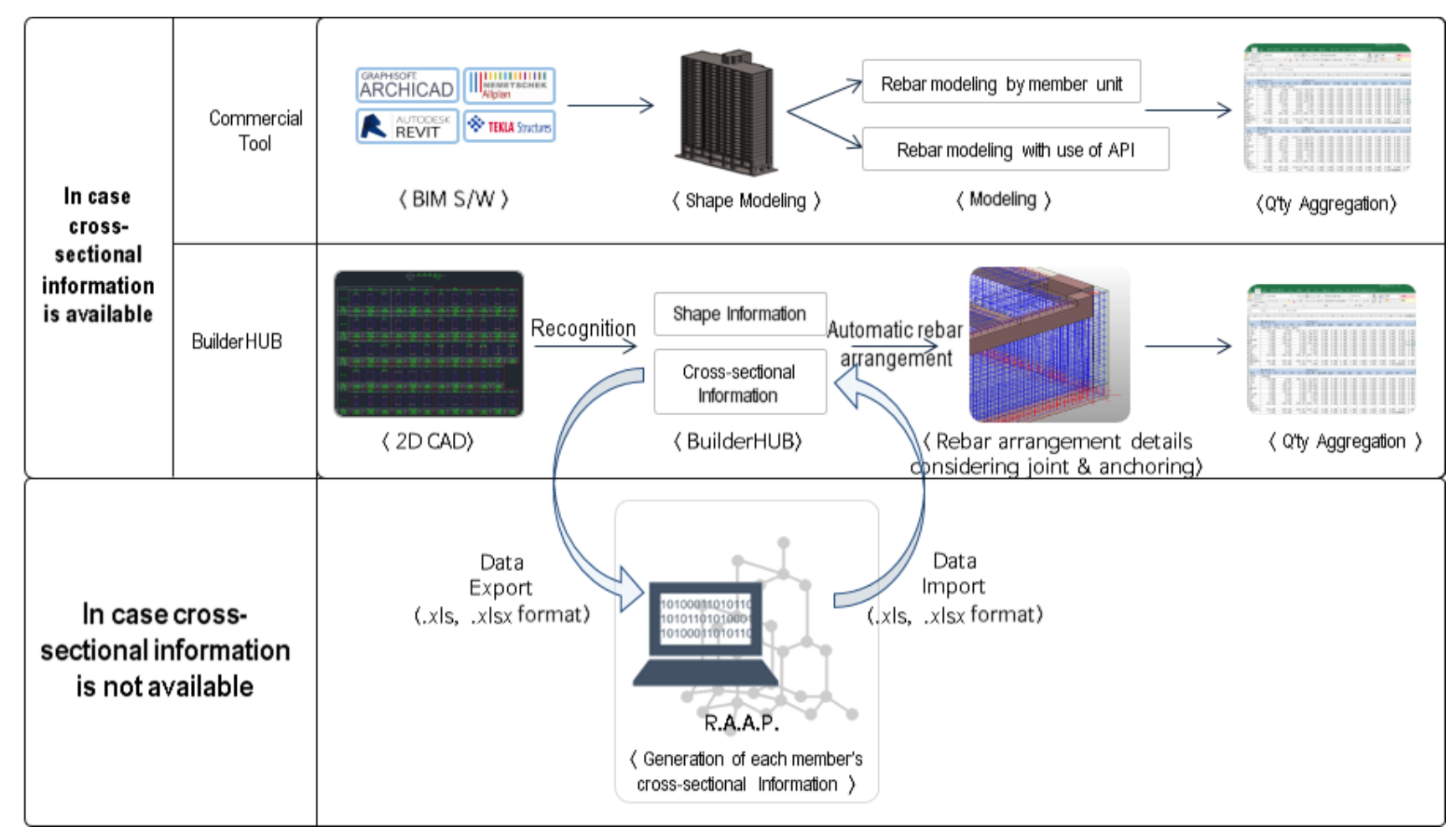

Fig. 4 Establishment of rebar quantity estimationtion process

\section{4. 철근 배근 자동화 프로그램(RAAP) 개발}

\section{$4.1 \mathrm{RAAP}$ 의 정보호환체계 및 프로세스}

초기 설계 단계 철근 물량을 산출하기 위한 각 소프트웨어 간 정보 호환체계 및 프로세스는 Fig. 5와 같다. 상용 $\mathrm{BIM}$ $\mathrm{S} / \mathrm{W}$ 의 호환문제는 국내에서 가장 많이 쓰이는 Revit과 $\mathrm{B} / \mathrm{H}$ 의 상호 호환으로 문제가 되지 않는다. 초기 설계 단계의 단면정보를 생성하기 위해 개발된 $\mathrm{RAAP}$ 와 $\mathrm{B} / \mathrm{H}$ 의 정보 교환은 .xls, .xlsx 형식으로 이루어진다. $\mathrm{B} / \mathrm{H}$ 에서 도면 인식을 통한 골조 형상을 모테링 후 RAAP에서 각 부재의 단면 정보를 생성해 주면 $\mathrm{B} / \mathrm{H}$ 에서 철근 모델링 및 물량 산출이

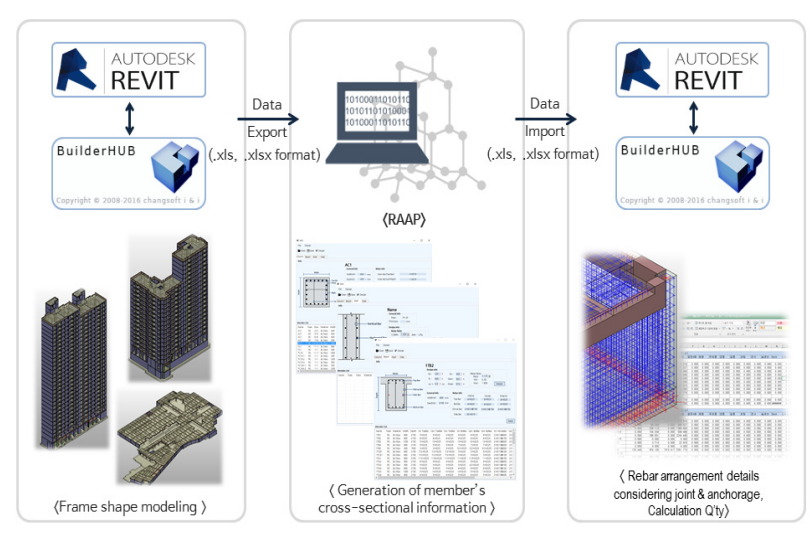

Fig. 5 The Information flow and process of RAAP
가능한 프로세스로 구성하였다.

\section{$4.2 \mathrm{RAAP}$ 에 의한 부재 단면 정보 생성}

본 연구에서의 철근 배근 알고리즘은 $\mathrm{B} / \mathrm{H}$ 에서 철근 배근 및 물량 산출에 필요한 정보를 토대로 구축하였으며, RAAP의 모든 부재는 건축 구조 기준 $(\mathrm{KBC} 2009)$ 을 기준에 의해 설계 되었다. Fig. 6 은 $\mathrm{B} / \mathrm{H}$ 의 각 부재에 필요한 배근 정보를 나타낸 화면이다.
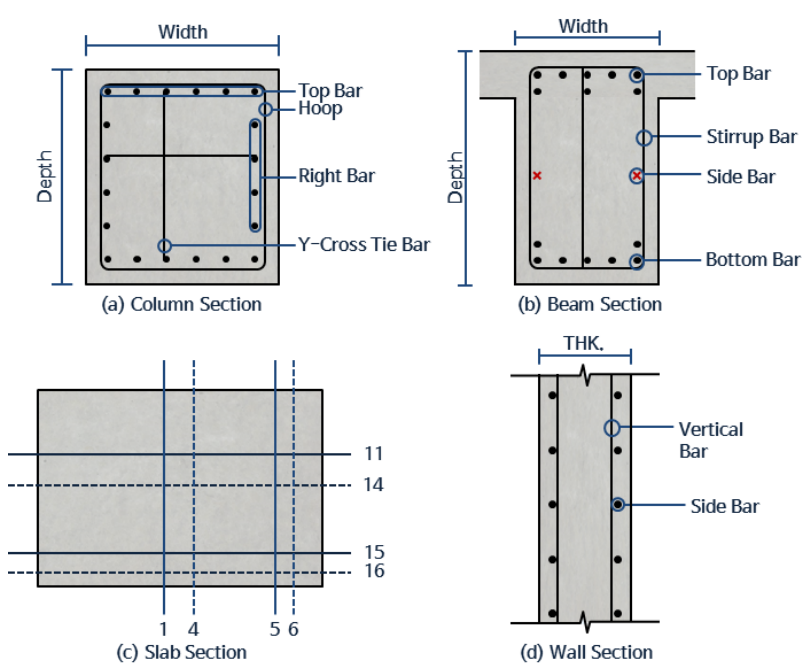

Fig. 6 Design of each element information 


\subsection{1 기둥 배근 설계 규정}

$\mathrm{B} / \mathrm{H}$ 는 기둥의 철근 배근을 위해 Top/Bottom Bar, Left/ Right Bar, Cen Hoop Bar, End Hoop Bar, X/Y Cross ${ }^{-}$ Tie Bar의 정보를 필요로 한다.

철근비 및 주근의 지름을 입력해 주고, 철근비의 경우 설계 기준에 따라서 1 4\%로 제한을 한다. 후프근은 주근이 D32 이하일 땐 D10으로 사용하며, D35이상일 땐 D13을 사용 한다. 이 최소한의 정보로 단면에 들어갈 수 있는 총 철근량 및 선택된 주근의 종류를 최대 몇 개까지 배근할 수 있는지 계산 한다. 계산된 철근의 개수를 단면의 비율로 Top/Bottom에 배근되는 개수와 Left/Right에 배근되는 개수를 산정하며, 주근 간격을 계산 및 검토한다. 주근의 간격은 (a) $40 \mathrm{~mm}$, (b) 주근의 1.5 배중 큰 값 이상으로 배근하며, 후프근의 배근은 단부와 중앙부로 나눠서 배근을 한다. 단부에서 후프근의 간격은 (a) 주근의 최소 지름의 8 배, (b) 띠철근 지름의 24 배, (c) 골조 부재 단면의 최소치수의 $1 / 2$ 배, (d) $300 \mathrm{~mm}$ 중 최소값 이하로 배근을 하며, 중앙부는 단부 배근 간격의 2 배 이하로 배근을 한다. Cross Tie bar의 경우에는 X방향과 $\mathrm{Y}$-방향으로 구분을 하며, 주근과 주근 사이의 순간 격에 따라서 배치 방법이 다르다. 순간격이 $150 \mathrm{~mm}$ 이하일 경우 띠철근을 사용하지 않을 수 있는데, 연속된 2개마다 최소 1 개의 주철근은 띠철근으로 감싸야 하고, 순간격이 $150 \mathrm{~mm}$ 이상 떨어진 경우, 추가 띠철근을 배치해야 하는 기준을 따른다.

\section{2 .2 보 배근 알고리즘}

$\mathrm{B} / \mathrm{H}$ 상에서 보의 철근 배근을 위해선 내단부의 $\mathrm{Top}$, Bottom, Stirrrup Bar, 중앙부의 Top, Bottom, Stirrrup Bar, 외단부의 Top, Bottom, Stirrrup Bar 그리고 Side $\mathrm{Bar}$ 의 배근 정보를 필요로 한다.

보의 배근 알고리즘도 사용자가 철근비, 철근의 항복 강도, 근의 지름, 압축측 철근량은 인장측의 몇 $\%$ 로 할지 입력을 한다. 후프근은 기둥과 같은 방식으로 결정하며, 철근비는 최소 철근비와 최대 철근비로 제한을 둔다. 최소 철근비는 (a) $1.4 / f_{y}$, (b) $0.25 \times \sqrt{f_{c k}} / f_{y}$ 중 큰 값보다 큰 값으로, 최대 철근비는 $0.00255 \times \beta_{1} / \epsilon_{a, \min }+\epsilon_{c} \times f_{c k} / f_{y}$ 으로 계산된 값보다 작은 값으로 제한을 하였다 $\left(f_{c k}\right.$ : 콘크리트의 압축강도, $f_{y}$ : 철근의 항복강도, $\varepsilon_{a, \min }$ : 최소 허용 변형률, $\varepsilon_{c}$ : 허용 변형률, $\beta_{1}$ : 보정계수). 보에서 철근 배근을 단부와 중앙부로 나뉘고, 또, Top bar, Bot bar, Stirrup Bar로 나뉜다. 단부의 경우 단면의 크기와 철근비로 철근의 배근 가능 개수를 산정한다. 산정된 개수를 입력받은 압축측 철근비에 의하여 Top bar와
Bottom bar의 개수로 나누어준다. 주근의 순간격은 (a) $25 \mathrm{~mm}$, (b) $1.0 \mathrm{D}$, (c) 굵은 골재 최대치수의 $3 / 4$ 배 중 큰 값 이상으로 제한하며, 철근의 개수가 많을 시엔 순간격을 고려하여 2 단으로 배근을 한다. 전단 보강철근의 간격은 (a) 유효 깊이의 $1 / 4$, (b) 주근 직경의 8 배, (c) 후프근 직경의 24 배, (d) $300 \mathrm{~mm}$ 보다 작게 제한하였다. 전단 보강철근의 최소 단면적은 $0.35 \times b_{w} \times s / f_{y t}$ 계산하며, 후프근의 단면적 으로 나누어 전단 철근의 개수를 산정한다 $\left(b_{w}\right.$ : 보의 유효폭, $f_{y t}$ : 스터럽의 설계항복강도). 마지막으로 보의 깊이가 900 $\mathrm{mm}$ 이상인 보에 한하여 Side bar를 배근해 주며, 그 간격은 (a) $375 \times 210 / f_{s}-2.5 C_{c}$, (b) $300 \times 210 / f_{s}$ 중 작은 값보다 작게 설계하였다 $f_{s}$ : 사용하중상태에서 인장연단에 가장 가까이 위치한 철근의 응력, $C_{c}$ : 표피철근의 표면에서 부채 측면까지의 거리).

\section{2 .3 슬래브 배근 알고리즘}

$\mathrm{B} / \mathrm{H}$ 상에서 슬래브의 철근 배근을 위해서 Fig. 6에 표시된 바와 같이 No.1, No.4, No.5, No.6, No.11, No.14, No.15, No.16의 배근 정보를 필요로 한다.

슬래브의 경우엔 단위 길이당 수직, 수평철근비로 배근을 한다. $\mathrm{B} / \mathrm{H}$ 의 $\mathrm{DB}$ 에서 슬래브는 두께정보를 받아오고, 수직 및 수평 철근비를 입력받으며, 설계 기준에 따라서 최소 철근비는 $2 \%$ 로 제한한다. 그 후, 단면적과 철근비로 필요한 철근 배근 개수를 계산하고, 이 값을 이용하여 배근 간격을 산정한다. 단위 길이로 배근을 하여 배근 간격을 구하며, 배근 간격은 기준에 따라서 주근 및 부근의 중심간격을 위험 단면에서는 (a) Slab 두께의 2 배 이하, (b) $300 \mathrm{~mm}$ 이하로 제한하며, 기타 단면에서는 Slab의 두께의 3 배이하, 또는 $450 \mathrm{~mm}$ 이하로 제한한다.

\subsection{4 벽체 배근 알고리즘}

$\mathrm{B} / \mathrm{H}$ 상에서 벽체의 철근 배근을 구축하기 위해선 Vertical Bar, Horizontal Bar의 배근 정보를 필요로 한다.

벽체도 슬래브와 비슷한 방식으로 설계를 하며, 기준에 따라서 최소 수직 철근비와 최소 수평 철근비는 (a) 설계기준 항복강도 $400 \mathrm{Mpa}$ 이상으로 D16 이하의 이형철근은 0.0012 , 0.0020 , (b) 기타 이형철근은 $0.0015,0.0025$, (c) 지름 $16 \mathrm{~mm}$ 이하의 용접 철망은 $0.0012,0.0020$ 으로 제한을 둔다. 철근비로 철근량을 계산하여, 배근 가능한 개수를 산정 하고, 배근 간격을 구한다.

\subsection{RAAP UI}


본 연구를 통해 개발된 철근 자동 배근 프로그램 RAAP를 구현한 프로그램 언어는 Visual $\mathrm{C \#}$ 이며, 프로그램은 프로 그래밍 플랫폼인 Visual Studio 2015버전을 사용했다.

Fig. 7은 RAAP의 기둥 배근하는 유저 인터페이스(user interface)를 나타내며, 표시된 (1), (2), (3)은 각각 입력해야 하는 부분, 설계된 정보, 부재리스트를 나타낸 것이다.

Fig. 8은 기둥의 단면 정보생성을 위한 디자인화면을 나타낸 것이며 다른 부재들도 비슷한 형식으로 되어있다. 이

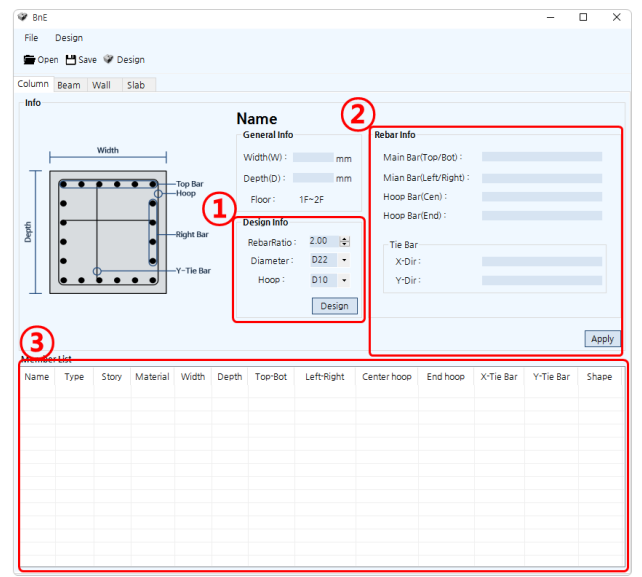

Fig. 7 RAAP's column UI

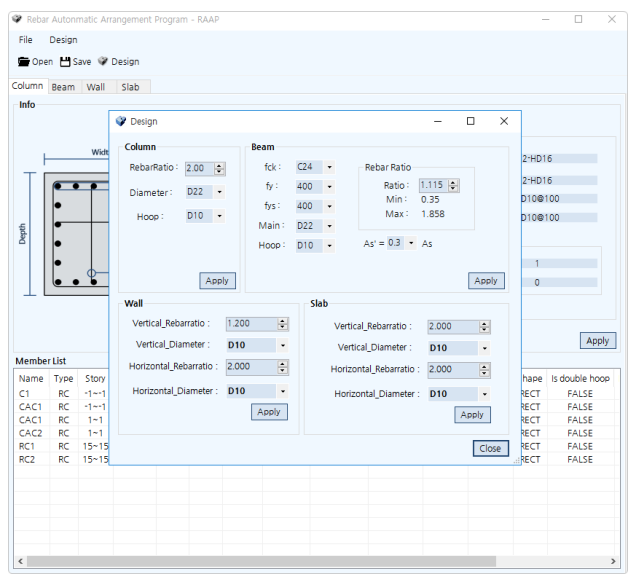

Fig. 8 RAAP's design UI

화면에서 주근 및 철근비 등 배근을 위한 최소한의 정보를 입력하게 된다. 입력된 정보로 각 부재의 단면 정보를 생성해 준다. 그 후 $\mathrm{B} / \mathrm{H}$ 로 정보는 내보내어 이음·정착을 고려한 상세 모델링 및 철근 물량 산출을 할 수 있다.

\section{5. 사례 적용 및 검증}

알고리즘을 검증 및 사례 적용을 위한 건물은 서울 근교의 25 층 내외의 공동주택으로 Fig. 9와 같이 5 동을 선정하였다. 알고리즘 검토 프로세스는 $\mathrm{B} / \mathrm{H}$ 에서 골조 형상 모델링을 해준 후 $\mathrm{RAAP}$ 로 단면 정보를 생성해 주고 $\mathrm{B} / \mathrm{H}$ 로 이음·정착이 고려된 상세모델 생성 및 물량 산출하는 과정으로 진행된다. 초기 설계 단계의 단면정보가 없는 상태에서의 물량을 산출을 목적으로 하며, 실제 프로젝트의 물량과 오차를 비교한다.

부재별로 여러 개의 철근비로 계산하여 실제 건물의 물량과 $\mathrm{RAAP}$ 으로 산출한 물량을 비교하였을 때, 오차가 가장 적은 철근비를 Table 2 Table 6에 나타내었다. 데이터들을 분석한 결과 공동주택의 경우, 모든 부재의 오차율이 최대 $5 \%$ 이내로 들어온 것을 확인하였다. 보와 기둥 부재의 오차율이 큰 것을 확인할 수 있는데, 슬래브와 벽체의 물량에 비하여 보와 기둥의 물량이 적어서 보와 기둥의 오차율이 커도 전체적인 물량에 미치는 영향이 적기 때문에, 초기 설계 단계의 물량을 실시 설계 단계의 물량과 큰 오차없이 산출이 가능했다.

Table 2 Comparison of quantities for building $A$

\begin{tabular}{|c|c|c|c|c|c|}
\hline & \multicolumn{2}{|c|}{$\begin{array}{c}\text { Rebar } \\
\text { ratio } \\
(\%)\end{array}$} & $\begin{array}{l}\text { Actual } \\
\text { quantity } \\
\text { (ton) }\end{array}$ & $\begin{array}{c}\text { RAAP } \\
\text { rebar quantity } \\
\text { (ton) }\end{array}$ & $\begin{array}{c}\text { Tolerance } \\
(\%)\end{array}$ \\
\hline Column & \multicolumn{2}{|c|}{2.30} & 5.486 & 5.675 & $3.45 \%$ \\
\hline Beam & \multicolumn{2}{|c|}{1.70} & 10.024 & 10.485 & $4.60 \%$ \\
\hline \multirow{2}{*}{ Slab } & $\mathrm{V}$ & 0.49 & \multirow{2}{*}{104.624} & \multirow{2}{*}{107.447} & \multirow{2}{*}{$2.70 \%$} \\
\hline & $\mathrm{H}$ & 0.50 & & & \\
\hline \multirow{2}{*}{ Wall } & $\mathrm{V}$ & 0.20 & \multirow{2}{*}{137.192} & \multirow{2}{*}{140.368} & \multirow{2}{*}{$2.32 \%$} \\
\hline & $\mathrm{H}$ & 0.20 & & & \\
\hline
\end{tabular}

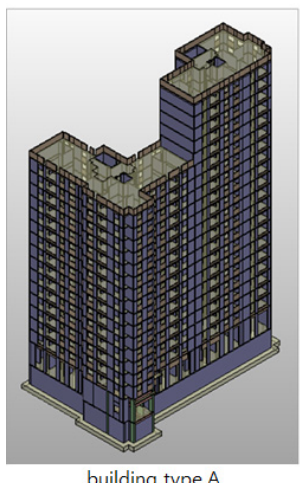

building type $\mathrm{A}$

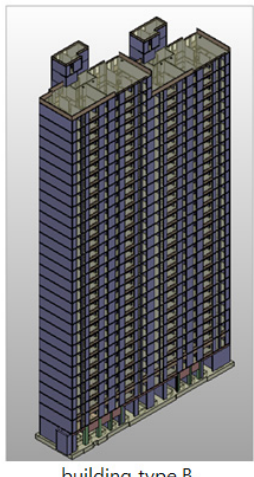

building type $B$

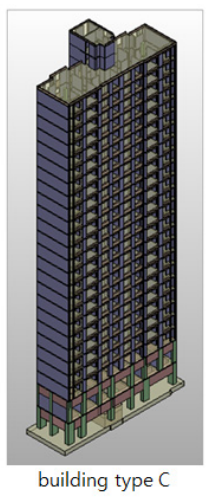

building type $\mathrm{C}$

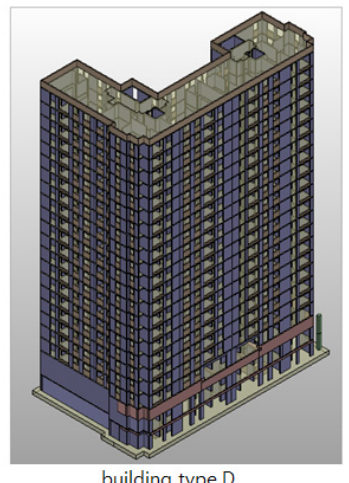

building type $D$

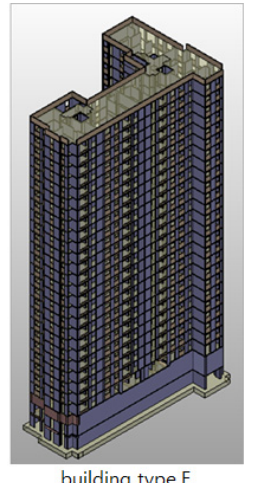

building type $\mathrm{E}$

Fig. 9 Apartment framework modeling 
Table 3 Comparison of quantities for building $\mathrm{B}$

\begin{tabular}{|c|c|c|c|c|c|}
\hline & \multicolumn{2}{|c|}{$\begin{array}{l}\text { Rebar } \\
\text { ratio } \\
(\%)\end{array}$} & $\begin{array}{l}\text { Actual } \\
\text { quantity } \\
\text { (ton) }\end{array}$ & $\begin{array}{c}\text { RAAP } \\
\text { rebar quantity } \\
\text { (ton) }\end{array}$ & $\begin{array}{c}\text { Tolerance } \\
(\%)\end{array}$ \\
\hline Column & \multicolumn{2}{|c|}{2.45} & 0.836 & 0.857 & $2.51 \%$ \\
\hline Beam & \multicolumn{2}{|c|}{1.45} & 9.127 & 9.461 & $3.66 \%$ \\
\hline \multirow{2}{*}{ Slab } & $\mathrm{V}$ & 0.60 & \multirow{2}{*}{115.157} & \multirow{2}{*}{117.554} & \multirow{2}{*}{$2.08 \%$} \\
\hline & $\mathrm{H}$ & 0.64 & & & \\
\hline \multirow{2}{*}{ Wall } & $\mathrm{V}$ & 0.22 & \multirow{2}{*}{165.125} & \multirow{2}{*}{168.419} & \multirow{2}{*}{$1.99 \%$} \\
\hline & $\mathrm{H}$ & 0.24 & & & \\
\hline
\end{tabular}

Table 4 Comparison of quantities for building $\mathrm{C}$

\begin{tabular}{|c|c|c|c|c|c|}
\hline & \multicolumn{2}{|c|}{$\begin{array}{l}\text { Rebar } \\
\text { ratio } \\
(\%)\end{array}$} & $\begin{array}{c}\text { Actual } \\
\text { quantity } \\
\text { (ton) }\end{array}$ & $\begin{array}{c}\text { RAAP } \\
\text { rebar quantity } \\
\text { (ton) }\end{array}$ & $\begin{array}{c}\text { Tolerance } \\
(\%)\end{array}$ \\
\hline Column & \multicolumn{2}{|c|}{2.60} & 0.379 & 0.383 & $1.06 \%$ \\
\hline Beam & \multicolumn{2}{|c|}{1.55} & 7.683 & 8.036 & $4.59 \%$ \\
\hline \multirow{2}{*}{ Slab } & $\mathrm{V}$ & 0.55 & \multirow{2}{*}{115.565} & \multirow{2}{*}{118.132} & \multirow{2}{*}{$2.22 \%$} \\
\hline & $\mathrm{H}$ & 0.57 & & & \\
\hline \multirow{2}{*}{ Wall } & $\mathrm{V}$ & 0.23 & \multirow{2}{*}{162.086} & \multirow{2}{*}{167.587} & \multirow{2}{*}{$3.39 \%$} \\
\hline & $\mathrm{H}$ & 0.25 & & & \\
\hline
\end{tabular}

Table 5 Comparison of quantities for building $D$

\begin{tabular}{|c|c|c|c|c|c|}
\hline & \multicolumn{2}{|c|}{$\begin{array}{l}\text { Rebar } \\
\text { ratio } \\
(\%)\end{array}$} & $\begin{array}{l}\text { Actual } \\
\text { quantity } \\
\text { (ton) }\end{array}$ & $\begin{array}{c}\text { RAAP } \\
\text { rebar quantity } \\
\text { (ton) }\end{array}$ & $\begin{array}{l}\text { Tolerance } \\
(\%)\end{array}$ \\
\hline Column & \multicolumn{2}{|c|}{2.68} & 1.044 & 1.082 & $3.64 \%$ \\
\hline Beam & \multicolumn{2}{|c|}{1.72} & 9.624 & 9.859 & $2.44 \%$ \\
\hline \multirow{2}{*}{ Slab } & $\mathrm{V}$ & 0.53 & \multirow{2}{*}{143.111} & \multirow{2}{*}{147.737} & \multirow{2}{*}{$3.23 \%$} \\
\hline & $\mathrm{H}$ & 0.55 & & & \\
\hline \multirow{2}{*}{ Wall } & $\mathrm{V}$ & 0.22 & \multirow{2}{*}{189.259} & \multirow{2}{*}{194.111} & \multirow{2}{*}{$2.56 \%$} \\
\hline & $\mathrm{H}$ & 0.20 & & & \\
\hline
\end{tabular}

Table 6 Comparison of quantities for building $E$

\begin{tabular}{|c|c|c|c|c|c|}
\hline & \multicolumn{2}{|c|}{$\begin{array}{l}\text { Rebar } \\
\text { ratio } \\
(\%)\end{array}$} & $\begin{array}{l}\text { Actual } \\
\text { quantity } \\
\text { (ton) }\end{array}$ & $\begin{array}{c}\text { RAAP } \\
\text { rebar quantity } \\
\text { (ton) }\end{array}$ & $\begin{array}{c}\text { Tolerance } \\
\quad(\%)\end{array}$ \\
\hline Column & \multicolumn{2}{|c|}{2.39} & 8.788 & 9.161 & $4.24 \%$ \\
\hline Beam & \multicolumn{2}{|c|}{1.68} & 13.409 & 13.803 & $2.94 \%$ \\
\hline \multirow{2}{*}{ Slab } & $\mathrm{V}$ & 0.57 & \multirow{2}{*}{88.994} & \multirow{2}{*}{91.153} & \multirow{2}{*}{$2.43 \%$} \\
\hline & $\mathrm{H}$ & 0.62 & & & \\
\hline \multirow{2}{*}{ Wall } & $\mathrm{V}$ & 0.23 & \multirow{2}{*}{140.639} & \multirow{2}{*}{144.574} & \multirow{2}{*}{$2.80 \%$} \\
\hline & $\mathrm{H}$ & 0.25 & & & \\
\hline
\end{tabular}

\section{6. 결 론}

본 연구에서는 $\mathrm{BIM}$ 기반 설계 현업에서 실용적인 철근 물량 산출 프로세스를 정리 및 제시하고, 초기 설계 단계의 단면 정보가 없는 상태에서 최소의 노력으로 기동, 보, 슬래브, 벽체의 철근 단면 정보를 자동으로 배근해 주는 프로그램인 $\mathrm{RAAP}$ 을 개발하였다. 또한 $\mathrm{BIM}$ 소프트웨어인 $\mathrm{B} / \mathrm{H}$ 의 이음. 정착 길이를 고려한 모델링 및 물량 산출 기능과 $\mathrm{RAAP}$ 를
연동하여 초기 설계 단계의 철근 물량 산출 프로세스를 구축 하였다. 본 연구를 통해 얻은 결론은 다음과 같다.

(1) 기존연구 및 BIM 소프트웨어 분석을 통해 건축 구조 분야에서 철골 구조의 경우 모델링, 도면화 및 물량 산출 등 대부분의 업무에서 $\mathrm{BIM}$ 의 적용이 점차 확대 되는 추세지만, 철근콘크리트 구조 특히, 철근 상세 모델링 분야에서는 다른 분야들보다 적용이 미비하다. 실무에 BIM도입이 어려웠던 문제에 대한 원인으로서 모델링 인력 및 비용 문제, BIM Tool의 기술적 한계, $\mathrm{BIM}$ 모델 활용의 한계 등이 존재하는 것을 도출하였 으며, 이에 따른 해결방안으로서 $\mathrm{B} / \mathrm{H}$ 의 기능으로 이음. 정착이 고려된 철근모델링 및 철근 물량 산출 프로 세스를 개선하고자 하였고, 본 연구에서 개발한 시스템 (RAAP)의 적용을 통해 초기 설계 단계에서 BIM기반 $\mathrm{RC}$ 구조의 철근 물량 산출 프로세스를 구축하고자 하였다.

(2) 부재 단면 크기를 포함한 골조 형상 BIM 모델이 있을 때, 각 부재의 단면에 합리적인 철근비를 가정하여 $\mathrm{RAAP}$ 로 주근과 보조근들을 배근을 해주고, $\mathrm{B} / \mathrm{H}$ 의 상세 설계 기능을 이용하여, 이음과 정착을 고려한 3 차원 배근을 완료한 결과 배근 상세 설계가 완료된 상태의 철근의 물량을 사람의 많은 노력없이 합리적인 물량을 집계할 수 있다.

(3) 본 연구에서는 공동주택을 대상으로 하였기에 모든 건물에 적용할 수 없는 한계성을 가지고 있으며, 향후 더 많은 건물 유형에 대한 연구가 진행되면 RAAP의 효용성이 극대화될 수 있을 것으로 판단된다. 또한, 추후 연구에서 부재의 철근비를 기존 통계 데이터 등을 활용하여 철근비 자체를 합리적으로 가정하는 알고리즘에 대한 추가적인 연구가 필요하다.

(4) 본 연구 결과는 건설프로젝트의 초기 설계단계에서 설계 진행상 구조 부재 단면 설계가 완료되지 않은 상태의 골조 물량 산출 시 적은 노력으로 기존의 $2 \mathrm{D}$ 기반 방식보다 신뢰성을 향상시킨 물량을 산출할 수 있는 기술로 발전시키는데 의미가 있으며, 합리적인 초기 설계 단계의 물량 산출 프로그램을 구축할 수 있는 기초 연구로서 활용될 수 있을 것으로 기대된다.

\section{감사의 글}

본 연구는 국토교통부 도시건축연구사업의 연구비 지원 (과제번호 : 15AUDP-B106327-01)에 의해 수행되었으며 이에 감사드립니다. 


\section{References}

Addison-Wesley, Addison-Wesley (2014) Essential C\# 5.0.

Architectural Institute of Korea (2009) KBC, Korean Building and Commentary.

Cho, Y.S., Kim, M..R., Hong, S.C. (2013) A Study on Automatic Reinforcement Placement System of Isolated Foundation based on S-BIM, J. Archit. Inst. Korea Struct.\& Constr., 29(11), pp.21 28.

Choi, H.C., Lee, Y.J., Lee, S.E., Kim, C.K. (2014) Development of 3-Dimensional Rebar Detail Design and Placing Drawing System, J. Comput. Struct. Eng. Inst. Korea, 27(4), pp.289 296.

Eom, J.E., Lee, J.H., Kim, J.H., Choi, I.S. (2014) An Introduction to a BIM-based Automated Reinforcement Modeling System, J. Comput. Struct. Eng. Inst. Korea, 27(3).

Hong, S.U., Cho, Y.S., Lee, J.H., Hong, S.C. (2011) The Study on Development of Automatic Reinforcement Placing System of Columns for RC Structures based on Parametric Technology, J. Archi. Inst. Korea Struct. \& Constr., 27(1), pp.11 18.

Hyundai Development Company (2010) Reinforced Concrete Reinforcement Details.

Information Publishing Group (2010) For beginners C\# exercises 200.

Jang, J.W. (2013) The Development of a Rebar Arrangement System for Reinforced Concrete by Applying the Structural BIM-based Lean Design Technique, Master's Thesis, Graduate School of Hanyang University.

Kim, M.S. (2014) Utilizability of BIM Software Tools in the Early Stage of Architectural Design Concentrated on Comparative Analysis among Major BIM Softwares, Reg. Assoc. Archi. Inst. Korea, 16(6) pp.65 72.

Park, S.H. (2014) C\# 5.0 Programming to Stimulate the Brain.

Park, Y.J., Won, S.K., Han, C. H., Lee, J.B. (2011) A Study on 3D BIM Collaborative Approximate Estimating.

최근에 각광받고 있는 $3 \mathrm{D} \mathrm{BIM기반} \mathrm{철근} \mathrm{물량} \mathrm{산출} \mathrm{현황을} \mathrm{살펴보면} \mathrm{상용} \mathrm{BIM}$ 도구들이 철근 모델링 기능을 제공하지만 그 기능을 이용해서 철근을 모델링하려고 하면 방대한 양의 모델링 시간이 소요가 되어 현재 실용적으로 사용할 수 있는 $\mathrm{BIM}$ 소프트웨어는 없다. 본 연구에서는 BIM 기반 설계 현업에서 실용적인 철근 물량 산출 프로세스를 정리 및 제시하고, 초기설계단계의 단면 정보가 없는 상태에서 기존의 $2 \mathrm{D}$ 방식에 비하여 보다 정확하게 기동, 보, 슬래브, 벽체의 철근 단면 정 보를 자동으로 배근해주는 프로그램인 Rebar Automatic Arrangement Program(이하 RAAP)을 개발하였다. 본 연구 결과는 건설프로젝트의 초기 설계단계에서 설계 진행상 구조 부재 단면 설계가 완료되지 않은 상태의 골조 물량 산출 시 적은 노력 으로 기존의 $2 \mathrm{D}$ 기반 방식보다 신뢰성을 향상시킨 물량을 산출할 수 있는 기술로 발전시키는데 의미가 있으며, 합리적인 초 기 설계단계의 물량 산출 프로그램을 구축할 수 있는 기초 연구로서 활용될 수 있을 것으로 기대된다.

핵심용어 : 초기설계단계, BuilderHub, BIM, 철근 배근 알고리즘, 골조 물량 산출 